\title{
Effect of Rice-based Fat Substitute on Gelation of Myofibrillar Proteins
}

\author{
Yuling Yang*, Yuan You, Xiaobei Peng, Yinji Chen, Yun Ma \\ College of Food Science and Engineering, Nanjing University of Finance and Economics/ Key Laboratory of Grain and Oils Quality \\ Control and Deep-Utilizing Technology of Jiangsu Province, Nanjing, 210046, China \\ *Corresponding author: yangyuling2014@126.com
}

Received December 31, 2014; Revised February 22, 2015; Accepted March 02, 2015

\begin{abstract}
This study was designed to investigate the effect of rice-based fat substitute (FS) on heat-induced gelation of myofibrillar proteins (MP) from chicken breast muscle. The secondary structure, calorimetric and rheological attributes ( $\alpha$-helix, $\beta$-sheet, heat flow and G') of FS and MP mixtures were measured during gel formation. The results indicated that the addition of FS led to easier denaturation of myosin but delayed denaturation of actin. The $\alpha$-helix content in the MP-FS mixture was lower than that of MP, whilst $\beta$-sheet content in the MP-FS mixture was higher than that of MP when heating temperature was higher than $60{ }^{\circ} \mathrm{C}$, indicating that the addition of FS could promoted MP molecules unfolding and aggregating at higher temperature. The G' value of the MP-FS mixture was higher than that of MP during heating. The initial gelling temperatures of the MP sample and the MPFS sample were $42{ }^{\circ} \mathrm{C}$ according to G' curves. The hardness value of the MP-FS gel was higher than that of the MP gel at temperature over $60{ }^{\circ} \mathrm{C}$, and reached the maximum value at $75^{\circ} \mathrm{C}$. Scanning electron microscopy showed that FS changed the microstructure of MP gel. It was concluded that the addition of FS promoted MP molecule unfolding, aggregating and gelling at heating temperature over $60^{\circ} \mathrm{C}$, but FS did not change the initial gelling temperature of MP molecules and the optimal gel-forming temperature.
\end{abstract}

Keywords: myofibrillar proteins, fat substitute, gelation, gel properties

Cite This Article: Yuling Yang, Yuan You, Xiaobei Peng, Yinji Chen, and Yun Ma, "Effect of Rice-based Fat Substitute on Gelation of Myofibrillar Proteins.” Journal of Food and Nutrition Research, vol. 3, no. 3 (2015): 152-156. doi: 10.12691/jfnr-3-3-4.

\section{Introduction}

The heat-induced protein gelation is generally known as a process that the native protein denature and their molecules unfold during heating, then the unfolding molecules aggregate and form gel matrix [1]. Myofibrillar proteins (MP) can form heat-induced gel [2]. Heat flow curves of MP measured by DSC may contain 2 or 3 peaks of denaturation temperature because of different experimental conditions [3,4,5,6]. MP may generally denature at 50-54, 57 and 63-66 ${ }^{\circ} \mathrm{C}$. MP molecules are unfolded and aggregated during heating accompanying with the decrease of $\alpha$-helix content and the increase of $\beta$ sheet content $[7,8]$. Liu observed that $\alpha$-helix content of fish myosin (the major component of MP) decreased from $85 \%$ to $38 \%$ when heated from $30^{\circ} \mathrm{C}$ to $80^{\circ} \mathrm{C}$ at $1{ }^{\circ} \mathrm{C} / \mathrm{min}$ [9].

MP gel properties are affected by many factors including such additives as carrageenan, soybean protein, starch and transglutaminase. Amako [10] reported that carrageenan had no effect on the thermal stability of MP from chicken breast but increased water holding capacity of the MP gel. Chin and co-workers [11] studied the effects of soy protein and transglutaminase on rheological properties of pork MP gel. Hong and Chin [12] studied the effects of alginate on the gel hardness of pork MP. Fat substitute (FS) is a key ingredient of low-fat meat surimi products. Rice-based fat substitute is the hydrolyzate of rice. The gelling process of rice-based FS has been reported by Yang and $\mathrm{Xu}$ [13]. The applications of ricebased FS in meat surimi products have been reported by Hsu [14] and Ju [15]. Few data are available on its effect on MP gelation process and gel properties. The objective of the present study was to investigate the effects of ricebased FS on the denaturation temperature, secondary structure, gel rheological and textural properties of MP from chicken breast muscle, to explore the effects of the FS on the gelation of MP.

\section{Materials and Methods}

\subsection{Materials}

Six-week-old commercial AA broilers were purchased from a commercial meat company.

\subsection{Extraction of MP}

MP was exacted from broiler breast muscle according to the procedure of Xiong et al. [16]. MP precipitate was stored at $4{ }^{\circ} \mathrm{C}$ and used within 3 days. 


\subsection{Preparation of Rice-based FS}

The rice-based FS was prepared according to the procedure of Yang and $\mathrm{Xu}$ [13]. Rice flour was slurried with deionized water to $20 \%$ concentration. The rice slurry was gelatinized at $90{ }^{\circ} \mathrm{C}$ for $20 \mathrm{~min}$ in a water bath with stirring (200 r/min). Then the rice slurry was hydrolyzed by $\alpha$-amylase until DE 2-3. $\alpha$-Amylase was inactivated by adding $1 \mathrm{~mol} / \mathrm{L}$ hydrochloric acid to $\mathrm{pH} 2.5$, then neutralized with $1 \mathrm{~mol} / \mathrm{L}$ sodium hydroxide $30 \mathrm{~min}$ later. The hydrolyzate was spray-dried. Thus, FS was obtained. DE value was determined using the method of Hizukuri, Takeda, Yasuda, and Suzuki [17].

\subsection{Measurement of MP Denaturation Temperature}

Samples were prepared containing $5 \mathrm{mg}$ MP, $5 \mathrm{mg}$ MP -2.5 mg FS, and $5 \mathrm{mg}$ MP- $5 \mathrm{mg}$ FS individually and sealed in the pans. MP thermal stability was measured using a DSC (Pyris1, Perkin-Elmer instrument Ltd), calibrated with indium. Each sample was scanned from 30 to $100{ }^{\circ} \mathrm{C}$ at a rate of $10{ }^{\circ} \mathrm{C} / \mathrm{min}$. The temperature and enthalpy were recorded during heating.

\subsection{Measurement of MP Secondary Structure}

The contents of $\alpha$-helix and $\beta$-sheet were measured using a circular dichrosim instrument (Chriascan, Applied Photophysics Co., UK). The parameters were: quartz cell $1 \mathrm{~cm}$, Temperature program conditions $30-80{ }^{\circ} \mathrm{C}$ by $2{ }^{\circ} \mathrm{C} / \mathrm{min}$. Each sample was scanned from 190 to $250 \mathrm{~nm}$ at a rate of $100 \mathrm{~nm} / \mathrm{min}$. The buffer was used as control. The MP sample concentration was $16 \mu \mathrm{g} / \mathrm{mL}$, whilst the MP-FS sample contained $16 \mu \mathrm{g} / \mathrm{mL}$ MP and $8 \mu \mathrm{g} / \mathrm{mL} \mathrm{FS.}$

\subsection{Measurement of Dynamic Rheological Properties}

Rheological properties were measured using a rheometer (MCR302 rheometer, Anton Paar Ltd., Austria). The measurement conditions were: $50 \mathrm{~mm}$ diameter parallel plate, gap $0.5 \mathrm{~mm}$, frequency $0.1 \mathrm{~Hz}$, and strain $2 \%$. The samples were heated from 30 to $75^{\circ} \mathrm{C}$ at a rate of $1{ }^{\circ} \mathrm{C} / \mathrm{min}$. $\mathrm{G}^{\prime}$ were automatically recorded during heating. MP sample concentration was $20 \mathrm{mg} / \mathrm{mL}$, whilst the MPFS sample contained $20 \mu \mathrm{g} / \mathrm{mL}$ MP and $10 \mu \mathrm{g} / \mathrm{mL}$ FS.

\subsection{Measurement of Textural Properties of the Heat-induced Gel}

MP solutions (30 mg/mL) and MP-FS solutions (30 $\mathrm{mg} / \mathrm{mL} \mathrm{MP,} 15 \mathrm{mg} / \mathrm{mL} \mathrm{FS}$ ) were heated from 30 to 45, 50, $55,60,65,70,75$ and $80^{\circ} \mathrm{C}$ at $1^{\circ} \mathrm{C} / \mathrm{min}$ in water bath, respectively, and kept the temperature until a total time of 50 minutes; then cooled to room temperature, and placed at $4{ }^{\circ} \mathrm{C}$ for 16 hours. The gels were used to determine the effects of heating temperature on gel textural properties.

To determine the effect of storage time on gel textural properties, the same concentration MP and MP-FS solutions were heated from 30 to $75{ }^{\circ} \mathrm{C}$ and kept the temperature for 5 minutes. The gels were then cooled to room temperature and stored at $4{ }^{\circ} \mathrm{C}$ for $20,40,60,80$, $100,120,140,160$, and 180 minutes, respectively.

Textural properties of the heat-induced gel were determined using a textural analyzer (TA.TX.Plus textural analyzer, Stable Micro Systems Ltd) with TPA program. The measurement conditions were: probe P/6, pre-test speed $5.0 \mathrm{~mm} / \mathrm{s}$, test speed $1 \mathrm{~mm} / \mathrm{s}$, post-test speed 5.0 $\mathrm{mm} / \mathrm{s}$, and distance $5 \mathrm{~mm}$.

\subsection{Scanning Electron Microscopy}

MP gel (40 mg/mL), MP-FS gel (40 mg/mL MP, 20 $\mathrm{mg} / \mathrm{mL} \mathrm{FS}$ ), and MP-FS gel (40 mg/mL MP, $40 \mathrm{mg} / \mathrm{mL}$ FS) were prepared and placed at $4{ }^{\circ} \mathrm{C}$ for 16 hours. The gel was fixed in 5\% glutaraldehyde, washed in phosphate buffer, fixed in 1\% osmic acid, dehydrated with ethanol, and dried by freeze-drying. The microstructure of gel was observed under a scanning electronic microscope (XL30w/lnca, Philips Ltd.) at accelerating voltage of $15 \mathrm{KV}$.

\subsection{Statistical Analysis}

All the experiments were triplicated. Data were analyzed by correlation analysis and multiple comparisons using SPSS 17.0.

\section{Results and Discussion}

\subsection{The Effect of FS on MP Denaturation Temperature}

DSC thermograms showed that both MP and MP-FS samples had two distinct endothermic transition peaks. Peak 1 and peak 2 were attributed to myosin and actin, respectively $[5,18]$. The denaturation temperature of myosin in the MP sample was $\mathrm{T}_{\mathrm{o}} 54.51{ }^{\circ} \mathrm{C}, \mathrm{T}_{\mathrm{p}} 58.99{ }^{\circ} \mathrm{C}$, $\mathrm{T}_{\mathrm{e}} 62.86{ }^{\circ} \mathrm{C}$; whilst that of myosin in MP-FS(1:1) sample was $\mathrm{T}_{\mathrm{o}} 51.96{ }^{\circ} \mathrm{C}, \mathrm{T}_{\mathrm{p}} 57.77{ }^{\circ} \mathrm{C}, \mathrm{T}_{\mathrm{e}} 66.63{ }^{\circ} \mathrm{C}$ (Table 1), which indicated that addition of FS destabilized myosin and widened the denaturation temperature range of myosin. The $\mathrm{T}_{\mathrm{p}}$ values of actin from MP, MP- FS (2:1) and MP- FS (1:1) were $69.80,74.80{ }^{\circ} \mathrm{C}$ and $78.88{ }^{\circ} \mathrm{C}$, which suggested that addition of FS could stabilize actin. This may be due to the interaction between FS and MP. The rice-based FS contains approximately 90\% maltodextrin, and the only active group of maltodextrin molecules is hydroxyl. Therefore, the interaction between FS and MP must be hydrogen bonds.

Table 1. Effect of FS on MP denaturation temperature

\begin{tabular}{|c|c|c|c|c|c|c|}
\hline \multirow{2}{*}{ Samples } & \multicolumn{3}{|c|}{ Peak 1} & \multicolumn{3}{|c|}{ Peak 2} \\
\hline & $\mathrm{T}_{\mathrm{o}}\left({ }^{\circ} \mathrm{C}\right)$ & $\mathrm{T}_{\mathrm{p}}\left({ }^{\circ} \mathrm{C}\right)$ & $\mathrm{T}_{\mathrm{e}}\left({ }^{\circ} \mathrm{C}\right)$ & $\mathrm{T}_{0}\left({ }^{\circ} \mathrm{C}\right)$ & $\mathrm{T}_{\mathrm{p}}\left({ }^{\circ} \mathrm{C}\right)$ & $\mathrm{T}_{\mathrm{e}}\left({ }^{\circ} \mathrm{C}\right)$ \\
\hline $\mathrm{MP}$ & $54.51 \pm 0.01$ & $58.99 \pm 0.02$ & $62.86 \pm 0.02$ & $65.80 \pm 0.01$ & $69.80 \pm 0.01$ & $72.21 \pm 0.01$ \\
\hline MP-FS(2:1) & $53.58 \pm 0.02$ & $57.77 \pm 0.00$ & $64.72 \pm 0.01$ & $73.05 \pm 0.01$ & $74.80 \pm 0.01$ & $76.35 \pm 0.02$ \\
\hline MP-FS(1:1) & $51.96 \pm 0.0$ & $55.77 \pm 0.01$ & $66.63 \pm 0.01$ & $77.70 \pm 0.01$ & $78.88 \pm 0.02$ & $81.25 \pm 0.02$ \\
\hline
\end{tabular}

Some previous studies have shown that the interaction between meat protein and additives. Yang and co-workers [13] reported that the addition of gelatin led to easier denaturation of myosin because of the interaction between myosin and gelatin. Chen and co-workers [19] suggested that addition of flaxseed gum (FG) to salt-soluble meat 
protein (SSMP) could change the denaturation temperature of the protein because of the electrostatic interaction between SSMP and FG in gel formation. Ma [20] reported that the addition of $\kappa$-carrageenan to SSMP led to the disappearance of peak1 and the decrease of $T_{\text {peak } 2}$ because of the interaction between SSMP and $\kappa$-carrageenan. Ramirez and co-workers [21] found that the MP samples exhibited three endothermic peaks in DSC thermogram, and addition of wheat bran led to the decrease in the first $\mathrm{T}_{\mathrm{p}}$ and increase in the third $\mathrm{T}_{\mathrm{p}}$. The peak $\mathrm{k}_{1}$ and peak $\mathrm{k}_{3}$ of their DSC thermogram were corresponded to the peak and peak $\mathrm{k}_{2}$ in this present study. Therefore, wheat bran and the FS had the similar effect on MP denaturation.

\subsection{The Effect of FS on MP Secondary Structure}

The $\alpha$-helix content decreased from $95.77 \%$ to $45.05 \%$ when the MP was heated from 30 to $80{ }^{\circ} \mathrm{C}$ (Table 2). This is in accordance with previous studies [7,8,9]. The $\alpha$-helix content changes of MP-FS and MP samples during heating had the same trend. The initial $\alpha$-helix content of MP-FS was higher than that of MP (96.89\% vs 95.77\%). However, $\alpha$-helix content of MP-FS was $39.70 \%$, lower than that of MP $(45.05 \%)$ at $80{ }^{\circ} \mathrm{C}$ significantly $(p<0.05)$. The $\beta$-sheet content increased from $0.20 \%$ to $12.65 \%$ when the MP was heated from 30 to $80{ }^{\circ} \mathrm{C}$. The $\beta$-sheet content of MP-FS transformed faster than those of MP sample from 60 to $70^{\circ} \mathrm{C}(p<0.05)$. The decline of $\alpha$-helix content during heating indicated the unfolding of MP molecules, and the increase of $\beta$-sheet content meant the aggregating of the unfolding protein molecules [22]. Therefore, FS accelerated the unfolding-aggregating process of MP molecules at temperature higher than $60^{\circ} \mathrm{C}$, whilst it stabled the MP structure at temperature lower than $60{ }^{\circ} \mathrm{C}$. Few reports are available on effect of additives on the MP secondary structure.

Table 2. Effect of FS on secondary structure content of MP during heating

\begin{tabular}{|c|c|c|c|c|}
\hline \multirow{2}{*}{ Temperature $/{ }^{\circ} \mathrm{C}$} & \multicolumn{2}{|c|}{$\alpha$-Helix /\% } & \multicolumn{2}{|c|}{$\beta$-Sheet $/ \%$} \\
\hline & MP & MP-FS & MP & MP-FS \\
\hline 30 & $95.77 \pm 0.81 \mathrm{ab}$ & $96.89 \pm 1.10 \mathrm{a}$ & $0.20 \pm 0.03 \mathrm{~A}$ & $0.10 \pm 0.02 \mathrm{~A}$ \\
\hline 40 & $94.65 \pm 0.53 b$ & $95.86 \pm 0.05 \mathrm{ab}$ & $0.30 \pm 0.03 \mathrm{~A}$ & $0.21 \pm 0.01 \mathrm{~A}$ \\
\hline 50 & $89.14 \pm 0.05 d$ & $91.25 \pm 0.06 \mathrm{c}$ & $1.13 \pm 0.04 \mathrm{~B}$ & $0.86 \pm 0.01 \mathrm{~A}$ \\
\hline 60 & $75.89 \pm 0.09 e$ & $76.60 \pm 0.07 e$ & $4.02 \pm 0.02 \mathrm{C}$ & $3.75 \pm 0.07 \mathrm{C}$ \\
\hline 70 & $46.73 \pm 1.21 \mathrm{f}$ & $40.85 \pm 0.94 \mathrm{~h}$ & $12.05 \pm 1.03 \mathrm{D}$ & $14.13 \pm 1.04 \mathrm{E}$ \\
\hline 80 & $45.05 \pm 0.56 \mathrm{~g}$ & $39.70 \pm 0.96 \mathrm{~h}$ & $12.65 \pm 0.12 \mathrm{D}$ & $14.93 \pm 0.06 \mathrm{~F}$ \\
\hline
\end{tabular}

Note: Different letters in same row indicate significant difference $(p<0.05)$.

\subsection{The Effect of FS on MP Rheological Properties}

G' curves of MP and MP-FS samples showed similar trends during heating, and the G' values of MP-FS sample were higher than that of MP sample at the same temperature (Figure 1). G' of MP and MP-FS increased slowly at $42{ }^{\circ} \mathrm{C}$, which was the initial gelling temperature of the MP [16]. Therefore, addition of FS increased the elasticity of the samples, even if the initial gelling temperature of MP did not change.

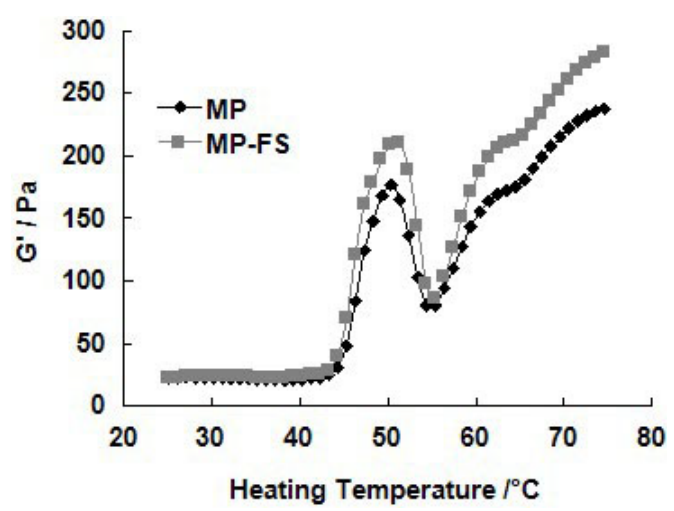

Figure 1. Effect of heating temperature on rheological properties of MP and MP-FS mixtures

Some additives have been reported to affect the rheological properties of muscle protein. The addition of chitosan to SSMP markedly increased the G' values over the entire temperature range [23]. $\kappa$-Carrageenan was also found to increase the complex modulus of SSMP [24]. The addition of gelatin to myosin also increased the $G$ ' values [25]. These three additives affected $G^{\prime}$ of MP because of physical interactions between additives and MP such as electrostatic interaction and hydrogen bond. In the present study, MP and FS interacted by hydrogen bond, which led to higher $G^{\prime}$ values.

\subsection{The Effect of FS on Textural Properties of MP Gel}

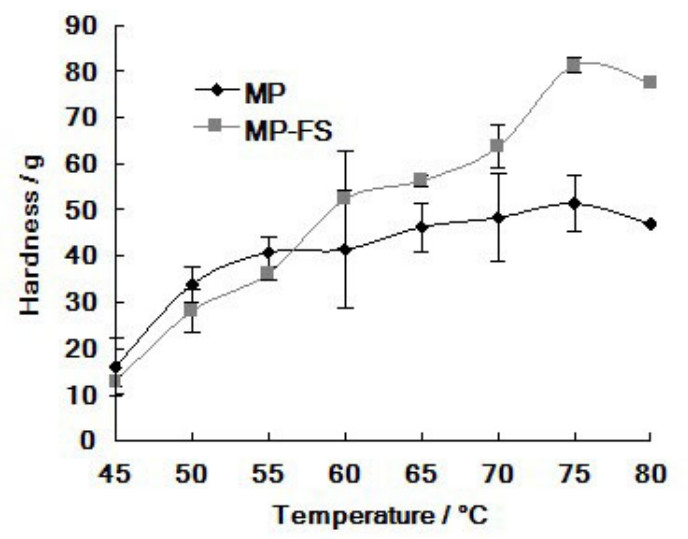

Figure 2. Effect of FS on hardness of MP gel and MP-FS mixed gel

The hardness of both heat-induced MP gel and MP-FS gel increased with temperature. They showed the maximum value of $51.4 \mathrm{~g}$ and $81.33 \mathrm{~g}$ at $75{ }^{\circ} \mathrm{C}$, respectively (Figure 2$)$. Because FS (15 mg/mL) could not form gel, it indicated that MP played a critical role in MPFS gel and there was interaction between MP and FS. The hardness of MP gel was higher than that of MP-FS gel at temperature lower than $55^{\circ} \mathrm{C}$; however the opposite situation appeared when the gels prepared at temperature higher than $55{ }^{\circ} \mathrm{C}$. The hardness of MP-FS mixed gel increased quickly from 55 to $75^{\circ} \mathrm{C}$, whilst the hardness of 
MP gel increased slowly. Furthermore, the decrease in the $\alpha$-helix and the increase in the $\beta$-sheet became faster above $60{ }^{\circ} \mathrm{C}$ (Table 2). This could be because FS was not soluble at lower temperature and the insoluble FS hindered MP gelling; but the solublized FS molecules interacted with MP molecules at higher temperature and accelerated MP molecules folding and aggregating, and finally resulted in higher hardness value of the gel.

There have been a few reports about the effects of polysaccharides on the gel hardness of muscle protein. Ma [20] and Verbeken [24] reported that $\kappa$-carrageenan could increase the gel hardness of SSMP at proper conditions.

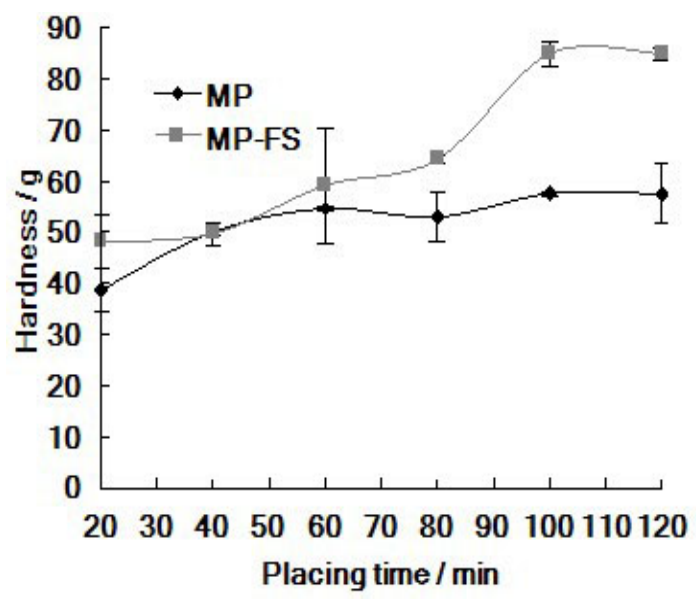

Figure 3. Effect of placing time on hardness of MP gel and MP-FS mixed gel

The effect of FS on textural properties of MP was not only related to the temperature of the gel preparation, but also to the storage time of the gel. The hardness of MP gel stored at $4{ }^{\circ} \mathrm{C}$ increased within the first $40 \mathrm{~min}$ but not change afterwards. However, the hardness of the MP-FS mixed gel increased significantly till 100 min (Figure 3).
This is because the maltodextrin in FS continued to gel at $4{ }^{\circ} \mathrm{C}$. Yang et al [13] reported that the gel strength of ricebased FS increased at $4{ }^{\circ} \mathrm{C}$ within $8 \mathrm{~h}$. Therefore, the interaction between MP and FS and the FS gelation led ultimately to higher hardness for the MP-FS gel than the MP gel. In addition, the presence of MP accelerated the gelation speed of FS.

\subsection{The Effect of FS on the Microstructure of MP Gel}

The gel matrix formed by MP was fine and uniform (Figure 4a). In MP-FS (2:1) mixed gel, both FS and MP molecules expanded into chain molecules. FS induced MP to forming a thick and strong gel matrix with bigger meshes, then FS molecules attached to the matrix, and entangled into fine gel network in the meshes (Figure 4b). Therefore, SEM demonstrated that the hydrogen bond was formed between FS and MP, which led to the changes of original microstructure of MP gel, and eventually led to changes of the gel properties such as gel hardness. When FS were added into MP samples at a ratio of MP to FS 1:1, the excess of FS existed in particle state and destroyed MP gel network structure (Figure 4c). Therefore, the suitable ratio of MP to FS was 2:1.

Sun [26] reported that adding peanut protein to chicken SSMP could improve the microstructure of the mixed gel and enhance the gel strength. Chin [11] also reported that adding sodium caseinate (SC) or soy protein isolate (SPI) to pork MP could make the gel network compact. Li and Xia [23] have observed that the gel network of SSMP and chitosan mixtures was compact and fine compared with that of SSMP. He considered that there were electrostatic interaction and hydrogen bond between SSMP and chitosan, which contributed to the improvement of the microstructure of the mixed gel.

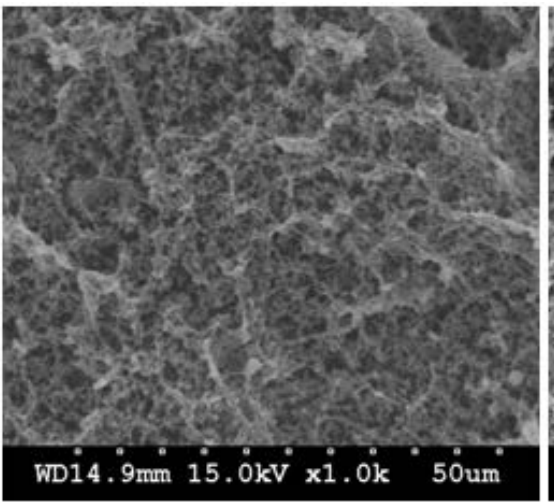

a MP

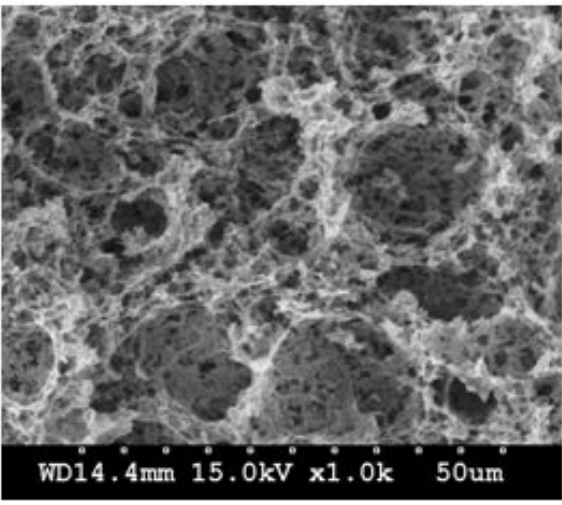

b MP-FS 2:1

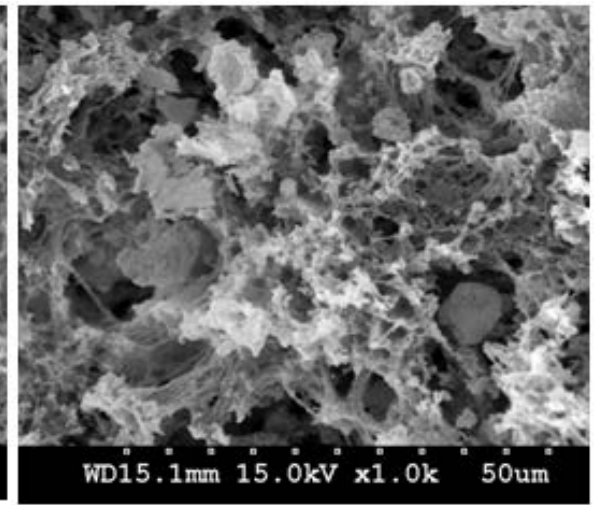

c MP-FS 1:1

Figure 4. Microstructure of MP gel and MP-FS gels

\section{Conclusions}

Rice-based fat substitute affected the heat-induced gelation of MP and the microstructure of MP gel because the FS interacted with MP by hydrogen bond. When the temperature was higher than $60^{\circ} \mathrm{C}$, the change rate of MP secondary structure in MP-FS sample was faster than that in MP sample, and the hardness of MP-FS mixed gel was higher than that of MP gel, which demonstrated that FS improved MP molecules unfolding and the unfolding molecules aggregating and gelling, and strengthened the gel at temperature over $60{ }^{\circ} \mathrm{C}$; whilst FS stablized the MP structure and weakened the MP gel at temperature lower than $60{ }^{\circ} \mathrm{C}$. Addition of FS didn't change the initial gelling temperature of MP and the optimal temperature of the gel prepared.

Addition of FS changed the original microstructure of MP gel. FS induced MP forming a thick and strong gel 
matrix with bigger meshes in the mixed gel, then FS molecules entangled into fine gel network in the meshes. The suitable adding amount of FS to MP was at ratio of MP to FS 2:1. In addition, the presence of MP accelerated the gelation speed of FS.

\section{Acknowledgments}

This work was supported by Natural Science Foundation of China (number: 31071570 and 31371798).

\section{References}

[1] Ziegler, GR. - Foededing, EA. The gelation of proteins. Advances in Food and Nutrition Research, 34, 1990, 203-280.

[2] Sano, T. - Noguchi, SF. - Tsuchiya, T. - Matsumoto, JJ. Dynamic viscoelastic behavior of natural actomyosin and myosin during thermal gelation. Journal of Food Science, 53(3), 1988, 924-928.

[3] Stabursvik, E. - Martens, H. Thermal denaturation of proteins in post rigor muscle tissue as studied by differential scanning calorimetry. Science of the Food and Agriculture, 31, 1980, 10341042.

[4] Wright, DJ. - Wilding, P. Different scanning calorimetric study of muscle and its proteins, myosin and its subfragments. Journal of the Science of Food and Agriculture 35, 1984, 357-372.

[5] Wang, SF. - Smith, DM. Dynamic rheological properties and secondary structure of chicken breast myosin as influenced by isothermal heating. Journal of Agricultural and Food Chemistry, 42, 1994a, 1434-1439.

[6] Lesiów, T. - Xiong, YL. Mechanism of rheological changes in poultry myofibrillar proteins during gelation. Avian and Poultry Biology Reviews 12(4), 2001, 137-149.

[7] Yongsawatdigul, J. - Park, JW. Thermal denaturation and aggregation of threadfin bream actomyosin. Food Chemistry, 83, 2003, 409-416.

[8] Hemung, BO. - Eunice, CY. - Chan, L. - Yongsawatdigul, J. Thermal stability of fish natural actomyosin affects reactivity to cross-linking by microbial and fish transglutaminases. Food Chemistry, 111(2), 2008, 439-446.

[9] Liu, R. - Zhao, SM. - Liu, YM. - Yang, H. - Xiong, SB. - Xie, BJ. - Qin, LH. Effect of $\mathrm{pH}$ on the gel properties and secondary structure of fish myosin. Food Chemistry, 121(1), 2010, 196-202.

[10] Amako, D. - Xiong, YL. Effects of carrageenan on thermal stability of proteins from chicken thigh and breast muscles. Food Research International, 34, 2001, 247-253.

[11] Chin, KB. - Go, MY. - Xiong, YL. Effect of soy protein substitution for sodium caseinate on the transglutaminate-induced cold and thermal gelation of myofibrillar protein. Food Research International, 42(8), 2009, 941-948.

[12] Hong, GP. - Chin, KB. Effects of microbial transglutaminase and sodium alginate on cold-set gelation of porcine myofibrillar protein with various salt levels. Food Hydrocolloid, 24, 2010, 444451.

[13] Yang, YL. - Xu, SY. Roles of components of rice-based fat substitute in gelation. Food Research International, 40(9), 2007, 1155-1160.

[14] Hsu, SY. - Sun, LY. Comparisons on 10 non-meat protein fat substitutes for low-fat Kung-wans. Journal of Food Engineering, 74, 2006, 47-53

[15] Ju, J. - Mittal, GS. Physical properties of various starch based fatsubstitutes. Journal of Food Processing and Preservation, 19, 1995, 361-383.

[16] Xiong, YL. A comparison of the reological characteristics of different fractions of chichen myofibrillar proteins. Journal of Food Biochemistry, 16, 1992, 217-227.

[17] Hizukuri, S. - Takeda, Y. - Yasuda, M. Multi-branched nature of amylose and the action of debranching enzymes. Carbohydrate Research, 94(2), 1981, 205-213.

[18] Xiong, YL. - Brekke, CJ. Thermal transitions of salt-soluble protein from pre- and postrigor chicken muscles. Journal of Food Science, 55(6), 1990, 1540-1543.

[19] Chen, HH. - Xu, SY. - Wang, Z. Interaction between flaxseed gum and meat protein. Journal of Food Engineering, 80(4), 2007, 10511059.

[20] Ma, F. - Chen, CG. - Zheng, L. - Zhou, CL. - Cai, KZ. - Han, Z. Effect of high pressure processing on the gel properties of saltsoluble meat protein containing $\mathrm{CaCl}_{2}$ and $\kappa$-carrageenan. Meat Science, 95(1), 2013, 22-26.

[21] Ramirez, JC. - Addo, K. - Xiong, YL. Gelation of mixed myofibrillar/wheat gluten proteins treated with microbial transglutaminase. Food Research International, 38, 2005, 11431149.

[22] Wang, CH. - Damodaran, S. Thermal gelation of globular proteins, influence of protein conformation on gel strength. Journal of Agricultural and Food Chemistry, 39(3), 1991, 433-438.

[23] $\mathrm{Li}, \mathrm{XK}$ - Xia, WS. Effects of chitosan on the gel properties of salt-soluble meat proteins from silver carp. Carbohydrate Polymers, 82, 2010, 958-964.

[24] Verbeken, D. - Neirinck, N. - Meeren, PVD. - Dewettinck, K. Influence of k-carrageenan on the thermal gelation of salt-soluble meat proteins. Meat Science, 70, 2005, 161-166.

[25] Yang, YL. - Zhou, GH. - Xu, XL. - Wang, Y. Rheological Properties of Myosin-Gelatin Mixtures. Journal of Food Science, 72(5), 2007, 270-275.

[26] Sun, JX. - Wu, Z. - Xu, XL. - Li, P. Effect of peanut protein isolate on functional properties of chicken salt-soluble proteins from breast and thigh muscles during heat-induced gelation. Meat Science, 91, 2012, 88-92. 